\title{
Impact of plug-in hybrid electric vehicles on power system with high wind power penetration
}

\author{
Mahmoud Essam Harby ${ }^{1}$, Said Elsayed Elmasry ${ }^{2}$, Adel Elsamahy ${ }^{3}$, Luis Marroyo ${ }^{4}$, Javier Marcos $^{5}$ \\ ${ }^{1,2,3}$ Faculty of Engineering, Helwan University, Cairo, Egypt \\ ${ }^{4,5}$ Faculty of Engineering, Public University of Navarra (UPNA), Spain
}

\section{Article Info \\ Article history: \\ Received Feb 27, 2019 \\ Revised Apr 27, 2019 \\ Accepted May 11, 2019}

\section{Keywords:}

Plug-in hybrid electric vehicles Power system frequency control Smart grid

Vehicle-to-grid

Wind energy integration

\begin{abstract}
The rising energy independence and environmental concerns are key drivers in the growing popularity of plug-in hybrid electric vehicles (PHEVs). Because of the intermittent nature of the renewable energy sources, this may cause a high-frequency oscillation of the power system. From another aspect, all the PHEVs have in common the batteries, which provide the storage capability that can be effectively harnessed when the vehicles are integrated into the grid. Such a storage capability can effectively integrate wind power into the grid and all indicators signalize that the PHEVs are the most promising technology of the future transportation system. In this paper, different case studies are applied on one area power system to show the effect of the high wind energy penetration on the power system frequency and how the PHEVs can play an effective role in mitigating the power system frequency oscillation and supporting the more penetration of the wind energy into smarter electrical grids. In addition, an advanced controller has been designed to improve the frequency response and to compensate the delay of the system. The designed controller is a genetic algorithm (GA) based PID (proportional-integral-derivative) controller, it has been proposed for tuning optimized PID parameters. The results show that the controller has played an effective role in decreasing the response overshoot and settling time when used with the PHEVs. The used variable load, the thermal power plant parameters, and the wind turbine parameters are the same for the five case studies.
\end{abstract}

Copyright $\odot 2019$ Institute of Advanced Engineering and Science. All rights reserved.

\section{Corresponding Author:}

Mahmoud Essam Harby, Faculty of Engineering, Helwan University, Cairo, Egypt.

Email: 1eng.mahmoudessam@yahoo.com

\section{INTRODUCTION}

There are escalating anxieties nowadays about energy independence. Thus, this topic is a major political issue. In the recent twenty years, the world electrical energy generated from the renewable energy systems has been exploding, this is due to the many benefits of the renewable energy systems such as their abundant availability, helping in stabilizing the global energy prices, low running and maintenance cost and reduced carbon emissions [1].

The renewable resources are changeable, which leads to an imbalance between the generated power and the load demand, causing instability or oscillation on the power system frequency, this imbalance may cause a significant loss of loads or generation units, especially in small power systems like Canary Islands power system in the Atlantic Ocean and hence, the power system reliability will be affected due to this imbalance [2].

The ability to store energy when the supply or power generation from the renewable energy source exceeds the demand will be the door to the optimal exploiting of renewable energy. Because most of the 
renewable energy sources are changeable, so the storage is the suitable solution for both the times, they are available and not needed and those times when they are needed and not available. The basic idea is to keep exploiting the renewable energy source and power generation, regardless of the demand [3].

If the demand is less than the generated power from the renewable resource, the excess is diverted to a specific storage system. From another aspect, conventional energy storage systems reduce the energy efficiency and require an extra cost, infrastructure, a wide space and complex control system. Because of the several disadvantages of the conventional energy storage systems, new techniques and modern storage systems have been developed, one of these techniques is the usage of the PHEVs as a modern storage system [2].

Plug-in hybrid electric vehicles (PHEVs) have already entered the consumer automotive market and they will be an integral part of the electrical power system. There are three main types of electric vehicles (EVs), they are classed by the degree that the electricity is used as their main energy source, HEVs (Hybrid Electric Vehicles) like the Honda Civic Hybrid and Toyota Camry Hybrid, BEVs (Battery Electric Vehicles) such as BMW i3 and the Nissan Leaf, and PHEVs (Plug-in Hybrid Electric Vehicles) for example Toyota Prius. Table 1 represents a fruitful comparison between the basic three types of electric vehicles [4].

Table 1. Shows the comparison between electric vehicles types

\begin{tabular}{|c|c|c|c|}
\hline Type & $\mathrm{BEV}$ & $\mathrm{HEV}$ & PHEV \\
\hline Main Power Source & Battery & $\begin{array}{l}\text { Combustion } \\
\text { Engine }\end{array}$ & Battery \\
\hline $\begin{array}{c}\text { Secondary Power } \\
\text { Source }\end{array}$ & None & Battery & Combustion Generator \\
\hline $\begin{array}{c}\text { Source of Battery } \\
\text { Charging }\end{array}$ & $\begin{array}{c}\text { Grid Power } \\
\text { Regenerative Brakes }\end{array}$ & $\begin{array}{l}\text { Regenerative } \\
\text { Brakes }\end{array}$ & $\begin{array}{c}\text { Grid Power } \\
\text { Regenerative Brakes } \\
\text { Combustion Generator }\end{array}$ \\
\hline Advantages & $\begin{array}{c}\text { Emissions-Free } \\
\text { Greater Energy Efficiency } \\
\text { Lower Operating and } \\
\text { Maintenance Costs }\end{array}$ & $\begin{array}{c}\text { Improved fuel } \\
\text { economy } \\
\text { Reduced Emissions Compared } \\
\text { to Conventional Vehicles }\end{array}$ & $\begin{array}{l}\text { Best mileage from fuel } \\
\text { Environmentally Friendly }\end{array}$ \\
\hline Disadvantages & $\begin{array}{c}\text { Limited Travel Distance } \\
\text { Limited Charging Station } \\
\text { Availability } \\
\text { Long Charging Time }\end{array}$ & $\begin{array}{c}\text { Not as Fuel Efficient as PHEVs } \\
\text { Batteries cannot be Charged } \\
\text { Directly }\end{array}$ & $\begin{array}{l}\text { Expensive to Manufacture } \\
\text { Moderate Charging Time }\end{array}$ \\
\hline
\end{tabular}

From the previous comparison, it's obvious that the PHEVs are the best option for the world future transportation system from the practical point of view and the environmental point of view. This research studies the effect of the higher wind energy contribution on the power system frequency. In addition, it studies the impact of using the PHEVs as smart energy storage systems in the smart grids and how such systems can deal with the intermittent wind speed in the presence of the genetic algorithm (GA) based PID controller. These points are clarified through making a comparison between five main case studies in the next sections [2].

The five main case studies in this work are discussed separately in the next sections, then all case studies will be compared together to clarify the effect of the intermittent wind speed on the power system frequency and how the PHEVs can mitigate the effect of the wind speed variation on the power system frequency in the presence of the genetic algorithm (GA) based PID controller. This research is funded by Medsol project [5].

\section{A THERMAL POWER PLANT FEEDING A VARIABLE LOAD (REFERENCE CASE 1)}

In this case, the conventional power system consists of a thermal power plant feeding a changeable load as presented in Figure 1. This case is considered as the reference case and all other case studies will be referred to it as an evaluation of their responses. The variable load, the thermal plant power, and the power system frequency responses are clarified in Figure 2.

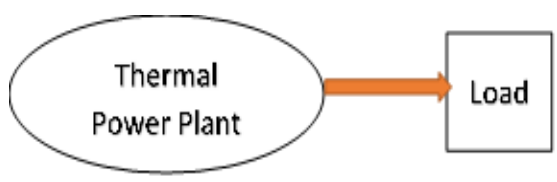

Figure 1. General layout of the conventional power system 

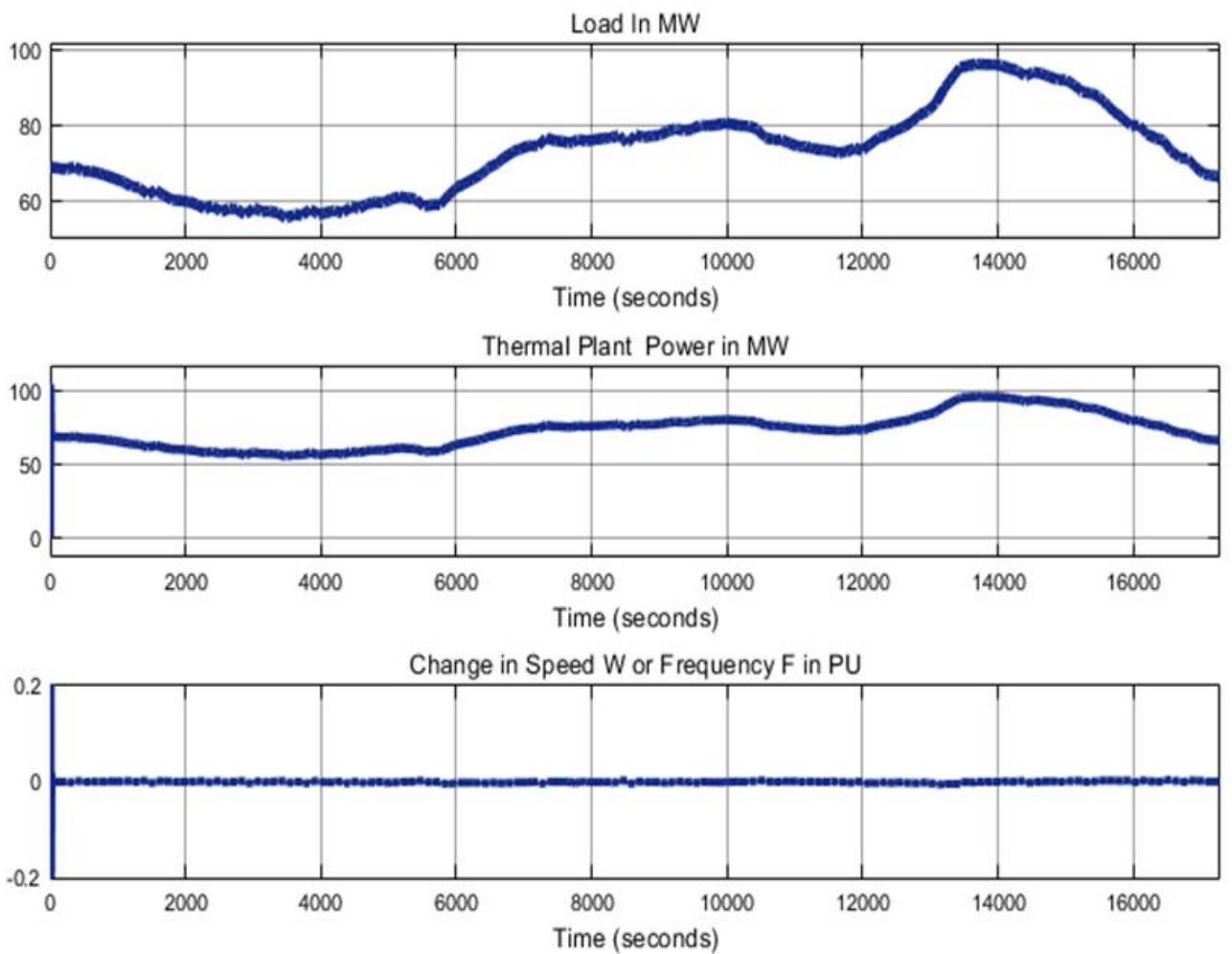

Figure 2. Results of the first case study

\section{A THERMAL POWER PLANT WITH FIVE WIND POWER UNITS FEEDING A VARIABLE LOAD (CASE STUDY 2)}

As described in Figure 3, five wind turbine units are used with the thermal power plant to feed the variable load. The variable load, the thermal plant power, the wind power, and the system frequency responses are illustrated in Figure 4. From the results, it's obvious that due to the wind power, there is fluctuation in the power system frequency, this oscillation increases as the contributions of the wind power increase into the power system.

\section{A THERMAL POWER PLANT WITH TEN WIND POWER UNITS FEEDING A VARIABLE LOAD (CASE STUDY 3)}

The proposed system is described in Figure 5. The different results are presented in Figure 6, the variable load, the thermal plant power, the wind farm power, and the power system frequency responses are illustrated.

\section{A THERMAL POWER PLANT WITH TWENTY WIND POWER UNITS FEEDING A VARIABLE LOAD (CASE STUDY 4)}

The effect of the higher wind energy penetration on the power system frequency is still discussed in this section, and for this aim, twenty-wind turbine units are used to feed the variable load beside the conventional thermal power plant as clarified in Figure 7. The power system frequency response is illustrated in Figure 8. As noticed from the results, the more contribution of the wind energy, the more oscillation on the power system frequency, so different technologies are being used nowadays to smoothen the power system frequency during the wind speed fluctuations and to enhance the contribution of the renewable energy resources into the smart grids as discussed in the introduction. In the next case study Figure 9, one of the most reputable technologies nowadays is provided when using the genetic algorithm (GA) based PID controller. 


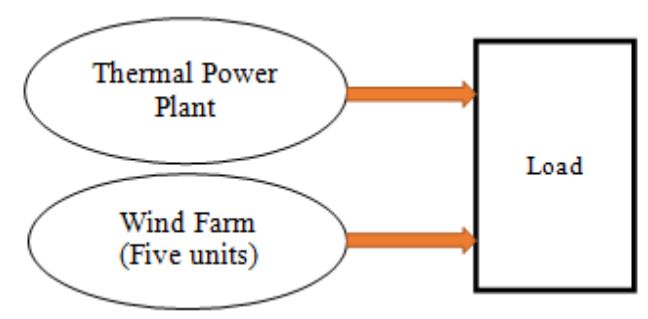

Figure 3. General layout of the proposed power system for the second case

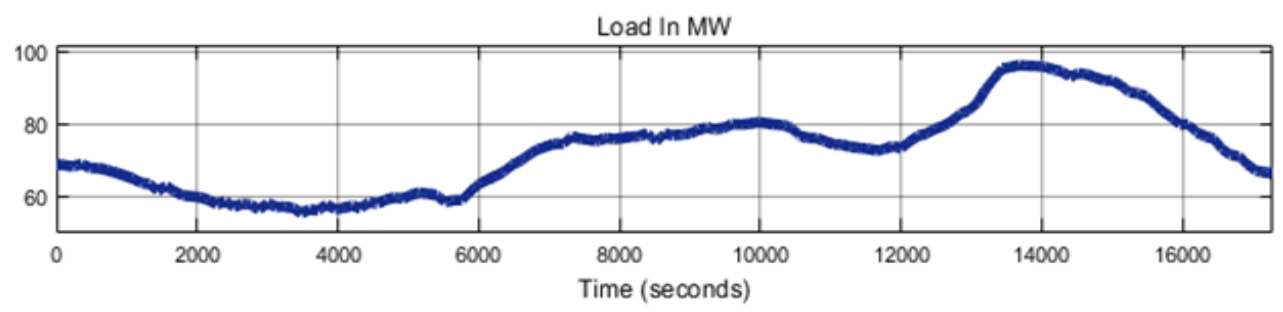

Thermal Plant Power MW

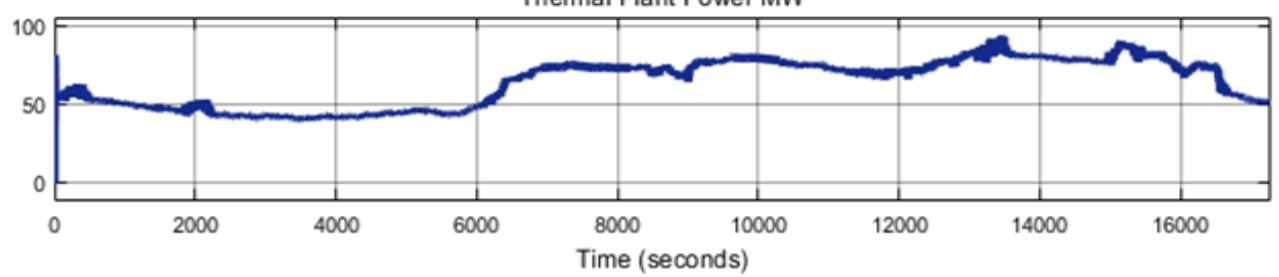

Change in Speed $\mathrm{W}$ or Frequency $\mathrm{F}$ in $\mathrm{PU}$
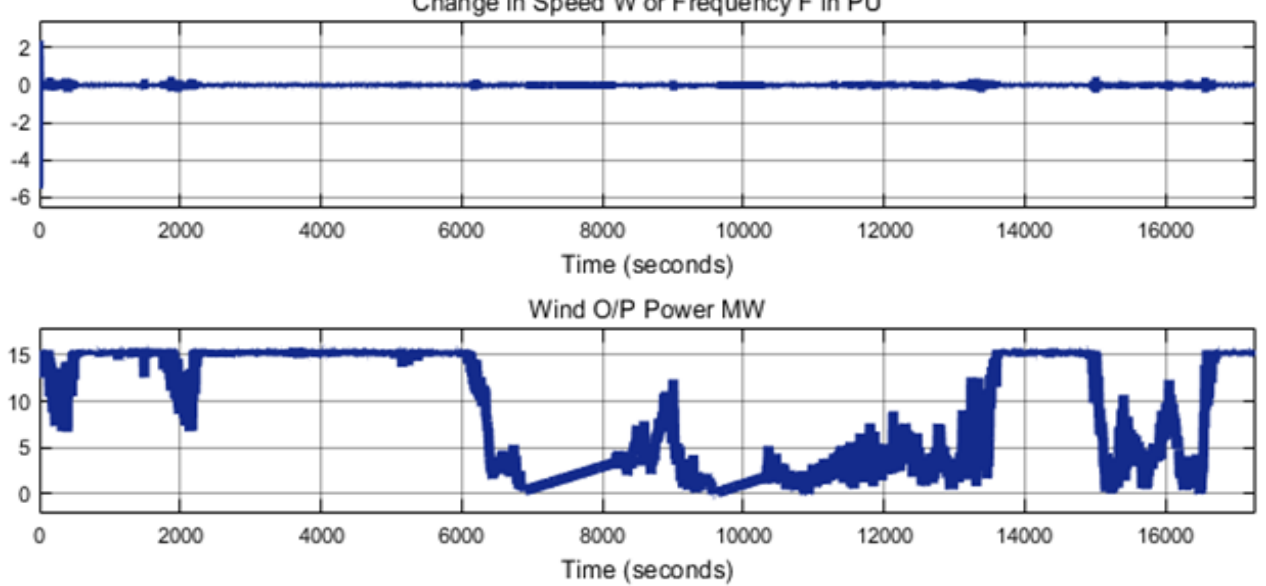

Figure 4. Results of the second case study

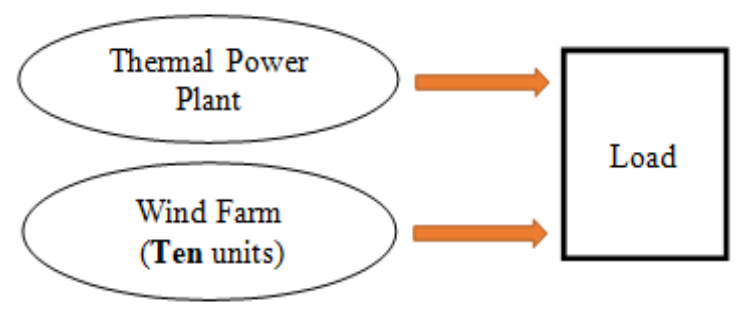

Figure 5. General layout of the proposed power system for the third case 

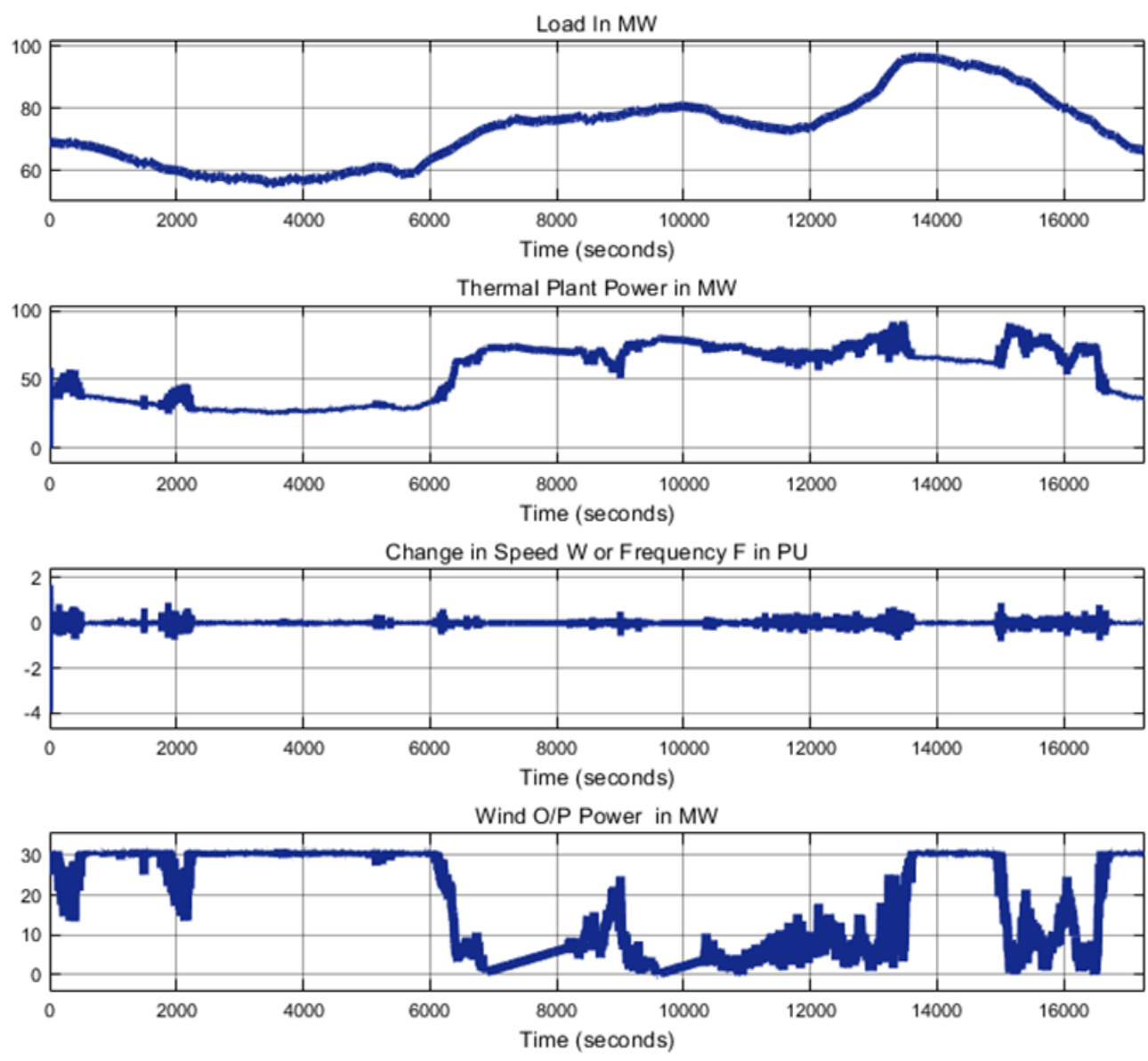

Figure 6. Results of the third case study

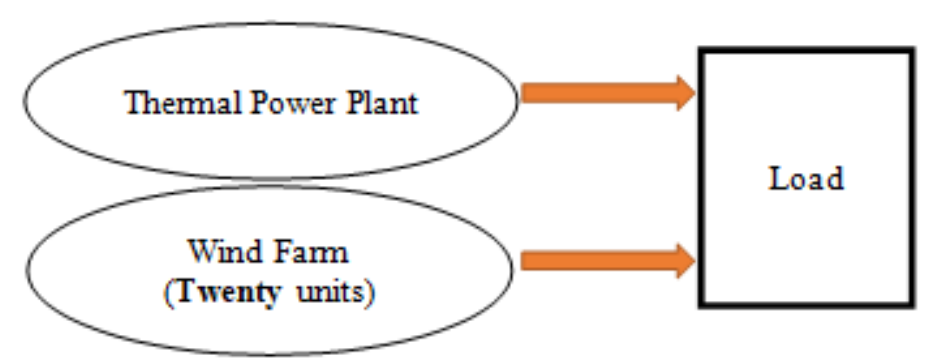

Figure 7. General layout of the proposed power system for the fourth case 

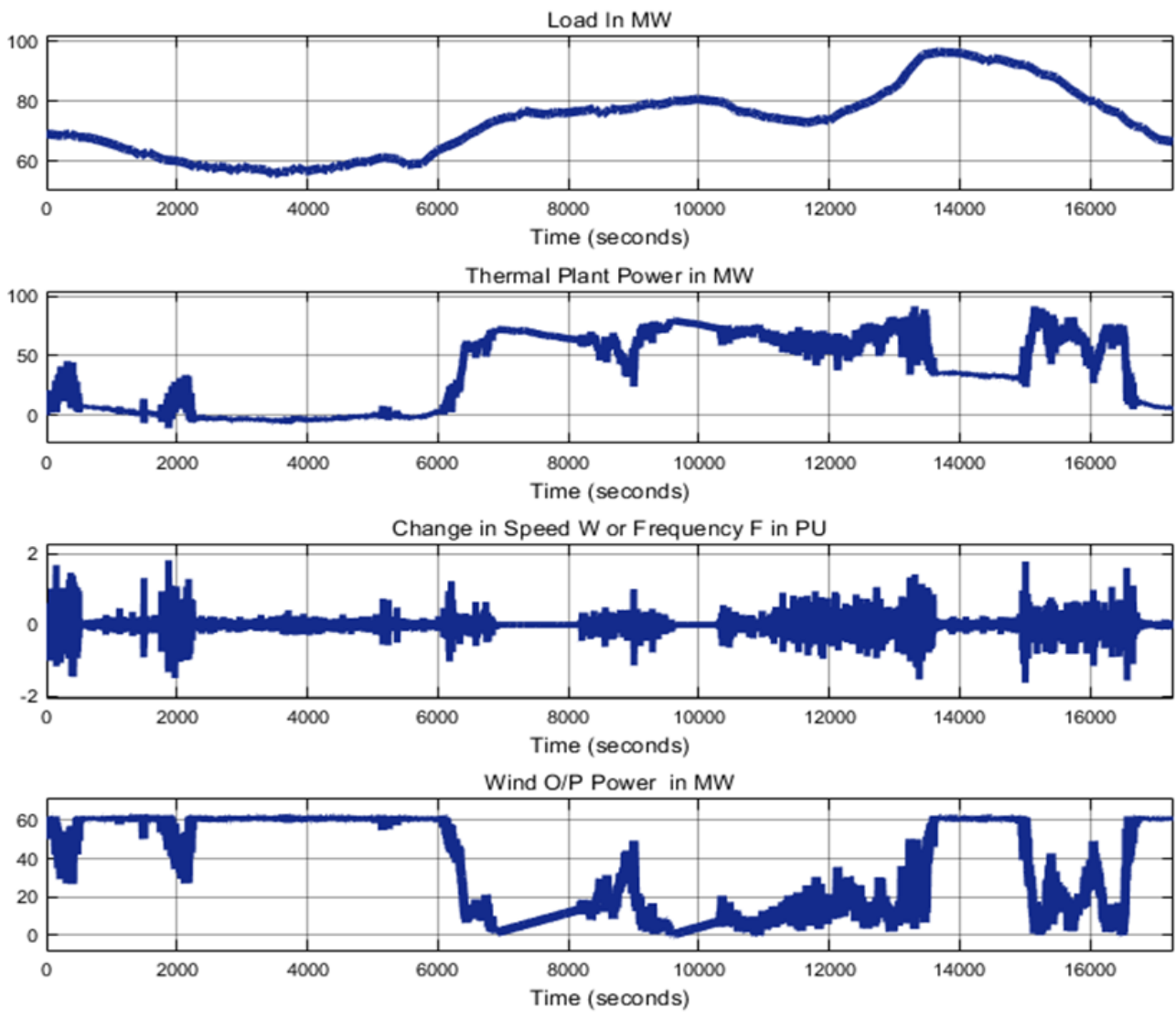

Figure 8. Results of the fourth case study

\section{A THERMAL POWER PLANT WITH TWENTY WIND POWER UNITS AND PHEVS FEEDING A VARIABLE LOAD (CASE STUDY 5)}

In Figure 9 is general layout of the proposed power system for the fifth case. The system frequency, the wind power, the conventional thermal plant power, the PHEVs contribution, and the variable load are illustrated in Figure 10. Following is a zoomed view of the PHEVs response Figure 11.

As illustrated in the results, the PHEVs present a lot of potential in supporting power systems with a high contribution of wind energy, since they can act as a quick response generator source in the vehicle to grid mode and vice versa, since they can act as a demand or load in the grid to vehicle mode (Charging mode) [6].

After studying each case individually, a fruitful comparison is provided in this section to show how effective is the PHEVs in smoothing the power system frequency during the wind speed fluctuations when using the genetic algorithm (GA) based PID (proportional-integral-derivative) controller. Figure 12 represents the frequency response for the five case studies. For more clarification, a small-time range is taken from the previous curve to show the comparison between the frequency responses of the five case studies as presented in Figure 13. 


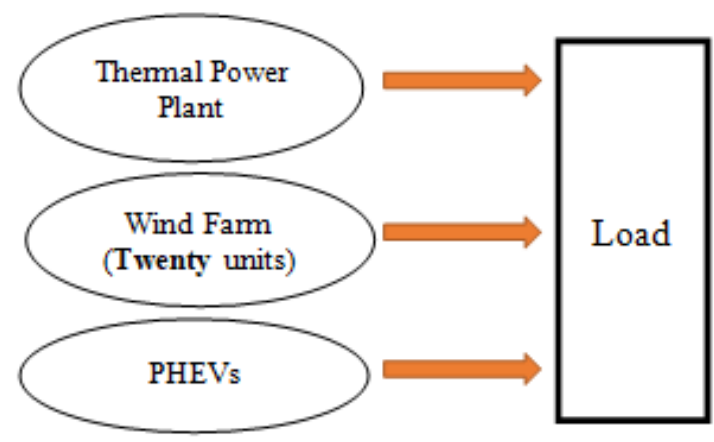

Figure 9. General layout of the proposed power system for the fifth case
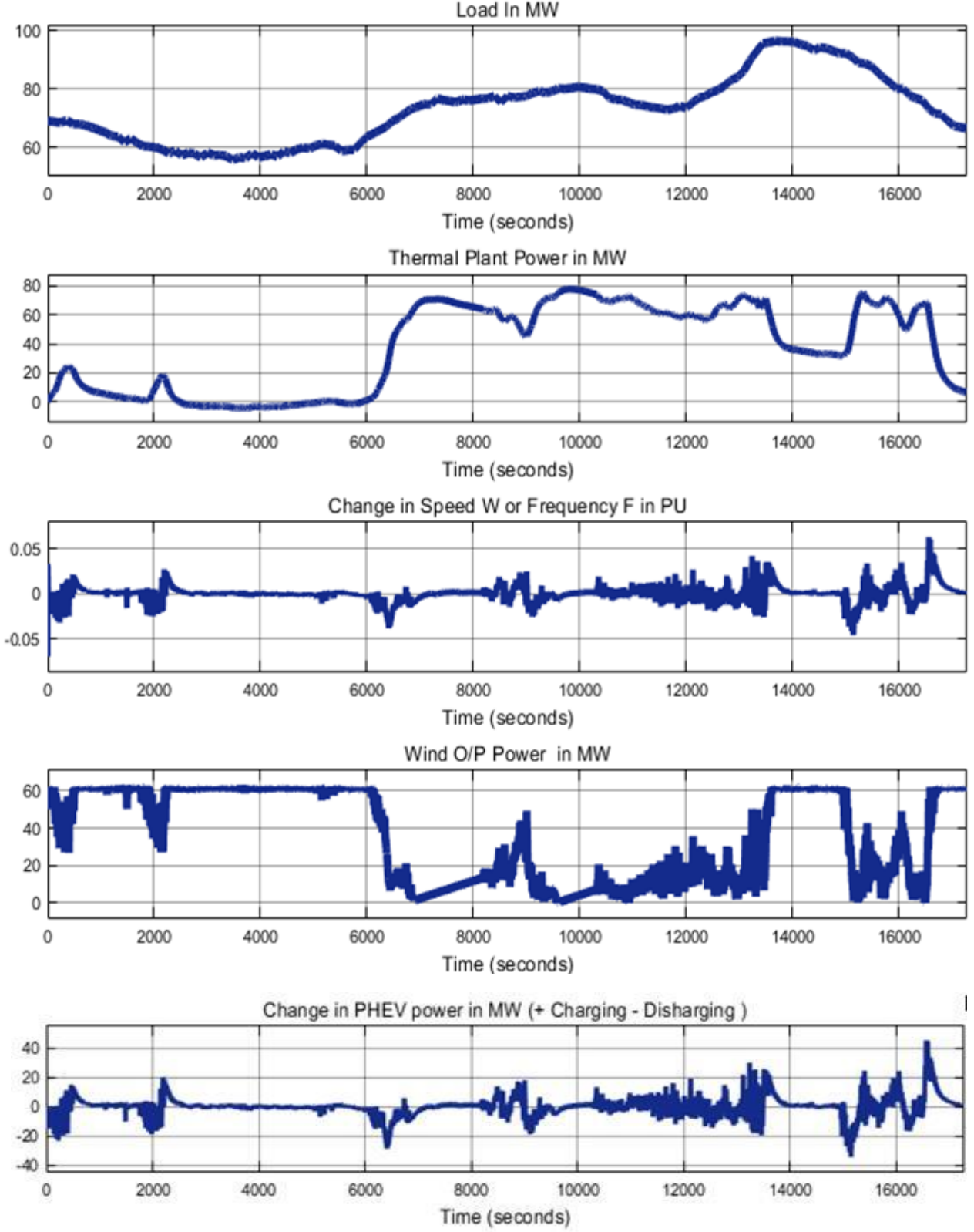

Figure 10. Results of the fifth case study 


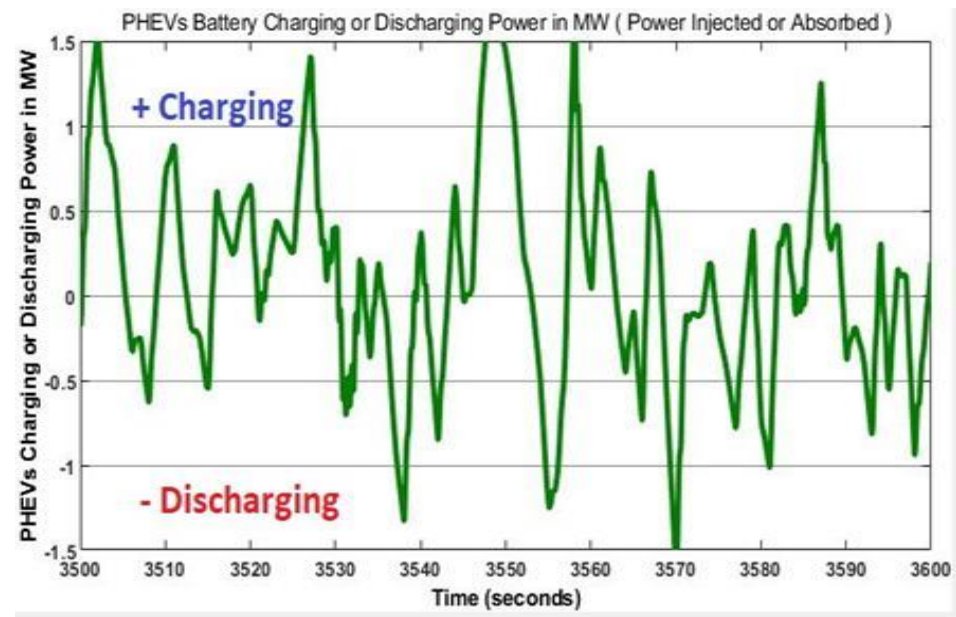

Figure 11. Zoomed view of the PHEVs response

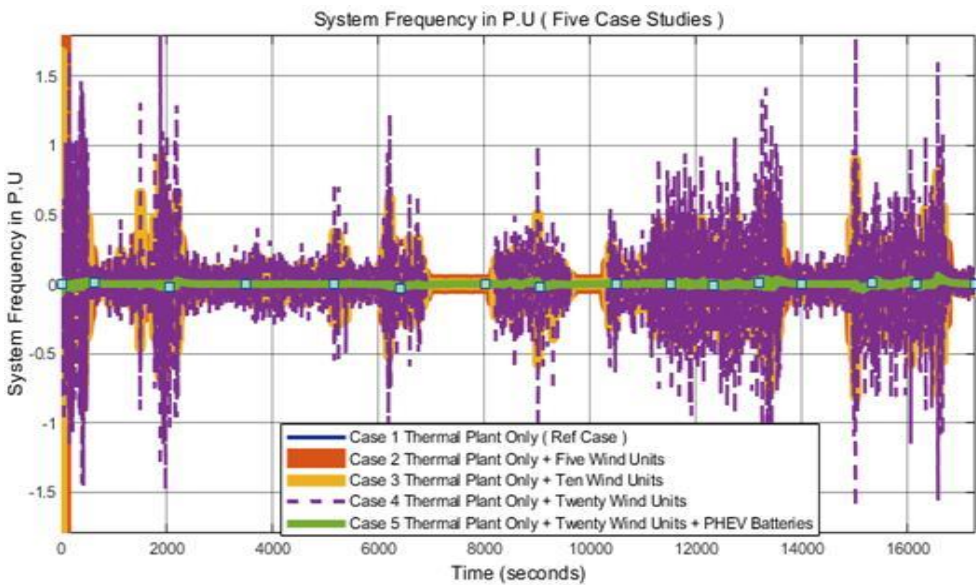

Figure 12. Comparison of the frequency responses of the five cases

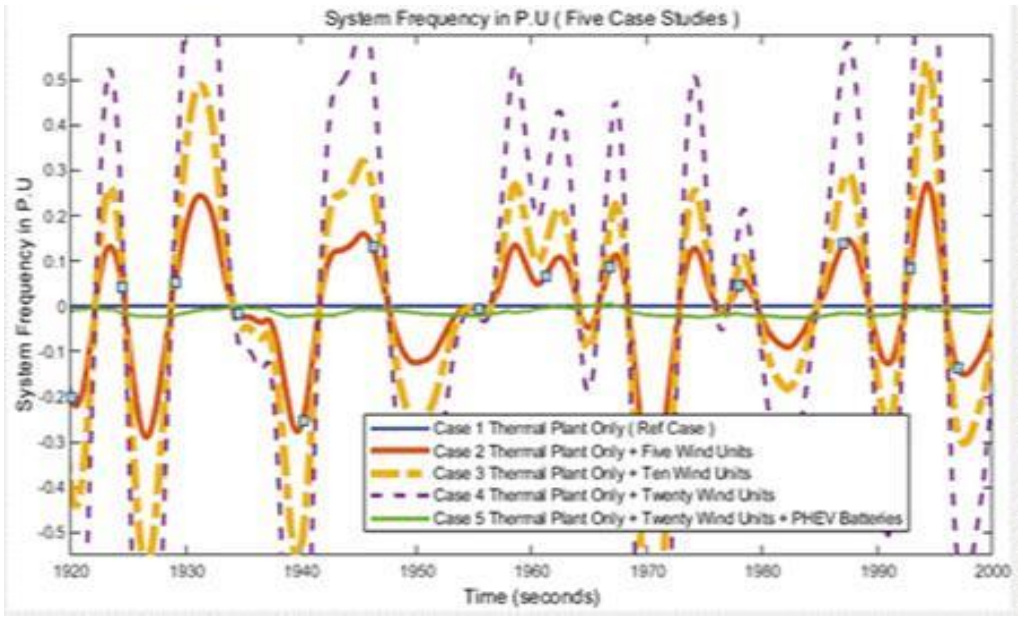

Figure 13. Zoomed view of the frequency response of the five cases 


\section{CONCLUSION}

As noticed from the results, the more contribution of the wind energy, the more oscillation on the power system frequency, so different technologies are being used nowadays to smoothen the power system frequency during the wind speed fluctuations and to enhance the integration of the renewable energy resources into the smart grids.

In this paper, an advanced controller has been designed to improve the frequency response and to compensate the delay in the system when using the PHEVs in a high wind energy penetration power system. The designed controller was a genetic algorithm (GA) based PID (proportional-integral-derivative) controller, it has been proposed for tuning optimized PID parameters and it was very effective.

The PHEVs have been used as a smart energy storage system to support the integration of the high wind energy into the power system in the presence of the genetic algorithm based PID controller. The PHEVs could act as a very fast response storage system. As far as future work is concerned, although power loss is not yet considered in this stage, it will be considered with the view to further enhancement of the system's efficiency. Moreover, future work will explore the possibilities of using a hierarchical framework to coordinate the centralized control base with a decentralized controller in each individual vehicle.

\section{REFERENCES}

[1] Vachirasricirikul, S. and Ngamroo, I., "Robust LFC in a smart grid with wind power penetration by coordinated V2G control and a frequency controller," IEEE Transactions on Smart Grid, 5(1), pp.371-380, 2014.

[2] Khodayar, M.E., Wu, L. and Shahidehpour, M., "Hourly Coordination of Electric Vehicle Operation and Volatile Wind Power Generation in SCUC," IEEE Trans. Smart Grid, 3(3), pp.1271-1279, 2012.

[3] Aghaei, J., Nezhad, A.E., Rabiee, A. and Rahimi, E., "The Contribution of plug-in hybrid electric vehicles in power system uncertainty management," Renewable and Sustainable Energy Reviews, 59, pp.450-458, 2016.

[4] Mi, C. and Masrur, M.A., "Hybrid electric vehicles: principles and applications with practical perspectives," John Wiley \& Sons, 2017.

[5] Saber, A.Y. and Venayagamoorthy, G.K., "Resource scheduling under uncertainty in a smart grid with renewables and plug-in vehicles," IEEE Systems Journal, 6(1), pp.103-109, 2012.

[6] Le, T.N., Al-Rubaye, S., Liang, H. and Choi, B.J., "Dynamic charging and discharging for electric vehicles in microgrids," In Communication Workshop (ICCW), 2015 IEEE International Conference on (pp. 2018-2022), IEEE. June 2015. 